Rev. Bras. Saúde Prod. Anim., Salvador, v.13, n.2, p.410-423 abr./jun., 2012 http://www.rbspa.ufba.br ISSN 15199940

\title{
Fezes equina como fonte de inóculo na obtenção de indicadores indigestíveis para estimar a digestibilidade em equinos
}

\author{
Horse feces as inoculum source for the obtaintion of indigestible markers to estimate \\ digestibility in equine
}

OLIVEIRA, Kátia de ${ }^{1 *}$; BITTAR, Carla Maris Machado² ${ }^{2}$ COSTA, Ciniro ${ }^{3}$; OLIVEIRA, Vinicius Antônio Baptista ${ }^{4}$; SÁ, Janaina Carolina de ${ }^{1}$

\footnotetext{
${ }^{1}$ Universidade Estadual Paulista, Curso de Zootecnia, Dracena, São Paulo, Brasil.

${ }^{2}$ Universidade de São Paulo, Escola Superior de Agricultura "Luiz de Queiroz, Departamento de Zootecnia, Piracicaba, São Paulo, Brasil.

${ }^{3}$ Universidade Estadual Paulistana,Faculdade de Medicina Veterinária e Zootecnia, Departamento de Melhoramento e Nutrição Animal, Botucatu, São Paulo, Brasil.

${ }^{4}$ Universidade Federal de Lavras, Lavras, Minas Gerais, Brasil.

*Endereço para correspondência: katia@dracena.unesp.br
}

\section{RESUMO}

Foram utilizados quatro cavalos castrados, por meio de delineamento em blocos casualizados. Objetivou-se viabilizar a obtenção in vitro das fibras indigestíveis, FDNi e FDAi, mediante a utilização, como inóculos, de líquido ruminal (LR) e fezes equina (FE), para estimar o coeficiente de digestibilidade nutrientes (CDN) de cavalos. Os tratamentos foram constituídos pelo método direto com a coleta total de fezes (CT) e indireto pelo uso das FDNi e FDAi obtidas por meio dos inóculos, LR e FE. Desta forma, no primeiro ensaio os equinos consumiram exclusivamente feno de coast-cross, e para o ensaio 2 os animais receberam $70 \%$ de feno de coast-cross e $30 \%$ de grãos de milho. Para o ensaio 1, a FDAi-FE, promoveu a melhor taxa de recuperação (TR) do indicador, o que a igualou ao grupo controle (CT), em 103,67\%, enquanto que as FDNi-LR e FDAi-LR resultaram as piores taxa de 83,43 e 88,28\%, respectivamente. As estimativas dos CDN foram adequadamente preditos pelas FDNi-FE e FDAi-FE. No ensaio 2 não se verificou efeito significativo do tipo de indicador e do método de obtenção na TR do indicador (valor médio de $101 \%$ ). As estimativas dos CDN foram adequadamente preditos pela FDAi, obtida por meio de ambos inóculos e FDNi, com o uso de fezes equina, para equinos alimentados com dieta mista. Concluiu-se que as fezes equina podem ser usadas como inóculo na obtenção das FDNi e FDAi, in vitro, em equinos alimentados exclusivamente com feno de coast-cross e na predição da digestibilidade de nutrientes, para cavalos que consomem dieta mista.

Palavras-chave: cavalo, indicador interno, método indireto e nutriente

\section{SUMMARY}

Four castrated horses were utilized in randomized blocks experimental design. The objective was to study the "in vitro" acquirement of indigestible fiber, neutral detergent fiber (NDFi) and acid detergent fiber (ADFi), using as inoculum source rumen fluid (RF) or horse feces (HF), to estimate the nutrient digestibility (ND) in horses. Treatments consisted of direct method by total feces collection (TC) and indirect method either by the use of NDFi or ADF by the use of LR or $\mathrm{HF}$ as inocula source. The first essay was done with horses fed coast-cross hay exclusively, while for the essay two, the horses were fed of $70 \%$ of 
Rev. Bras. Saúde Prod. Anim., Salvador, v.13, n.2, p.410-423 abr./jun., 2012 http://www.rbspa.ufba.br ISSN 15199940

coast-cross hay and $30 \%$ corn grain. For the essay 1, ADFi-HF presented the best marker recuperation rate (RR) $(103.67 \%)$, being similar to control (TC), while NDFi-RF and ADFi-RF resulted in lower $\mathrm{RR}(\mathrm{P}<0.05), 83.43$ and $88.28 \%$, respectively. The ND was adequately estimated by NDFi-HF and ADFi-HF. On the second essay there were no significant effects of the marker type, as well as for the indigestible marker acquirement method, for the marker RR (average value of $101 \%$ ). The ND was adequately predicted by the ADFi obtained for both innocula source and NDFi obtained by the use of HF as inoculum, for horses fed a mixed diet. It can be concluded that horse feces may be used as inoculum source for the acquirement of NDFi and ADFi "in vitro" for digestibility determination on horses fed coastcross hay exclusively, as well as for horses fed a mixed diet.

Keywords: horse, indirect method, internal marker and nutrient

\section{INTRODUÇÃO}

A busca por estimar acuradamente as exigências dos animais e o valor nutritivo dos alimentos tem aumentado o interesse no desenvolvimento de métodos alternativos de avaliação nutricional (PATTERSON et al., 2002, BEGERO et al., 2005; ALMEIDA \& SILVA, 2010). A técnica de digestão in vitro desenvolvida para uso em ruminantes (TILLEY \& TERRY, 1963), tem sido adaptada para equinos (ABDOULI \& BEM ATTIA, 2007; EARING et al., 2010). Contudo, as fermentações in vitro apresentam limitações inerentes à técnica, que impossibilita simular todas as situações ocorridas in vivo como, efeitos associativos, nível de ingestão e taxa de passagem (LATTIMER et al., 2007). Para esses casos, a estimativa da digestibilidade com indicadores internos deve ser considerada por contornar essas dificuldades.
Pioneiramente, resíduos de fermentação in vitro submetidos à extração com detergente neutro ou ácido foram propostos como indicadores internos indigestíveis, nas pesquisas em ruminantes (LIPPKE, 2002, OLIVEIRA JÚNIOR et al., 2004; WATANABE et al., 2010). De acordo com Oliveira et al. (2003), os indicadores indigestíveis, por ocasionarem superestimativa dos coeficientes de digestão da fração fibrosa de dieta foram classificados como inadequados para estudo em equinos. Stein et al. (2006), ao trabalharem com a mesma espécie animal verificaram que esses indicadores apresentaram boa acurácia e precisão, como indicador indigestível.

Independente da finalidade do uso do método in vitro (ensaio de digestão ou obtenção de indicadores indigestíveis), essa metodologia requer o emprego de inóculo microbiano preparado a partir da digesta ruminal, o que necessita de bovinos cirurgicamente preparados, e assim aumenta os custos com a manutenção. Alternativamente, o material fecal permanece em anaerobiose após a excreção, o que pode manter a microflora viável por horas, após deixar o trato digestivo (TUFARELLI et al., 2010). Desta forma, pesquisadores têm avaliado o uso de fezes de ruminantes, em comparação ao líquido ruminal, e obtido resultados satisfatórios nos estudos de digestibilidade (SILVA et al., 2003; LAUDADIO et al, 2009).

Dentro deste contexto, objetivou-se com este trabalho viabilizar a obtenção in vitro das fibras indigestíveis, mediante a utilização, como inóculos, de líquido ruminal e fezes equina para estimar a digestibilidade dos nutrientes de cavalos, em comparação ao método da coleta total de fezes. 


\section{MATERIAL E MÉTODOS}

Dois ensaios foram desenvolvidos na Sala de Metabolismo de Equinos, pertencente ao Departamento de Zootecnia da Universidade Federal de Lavras e no Laboratório de Nutrição Animal do Departamento de Zootecnia, ESALQ/USP. Quatro cavalos castrados, sem raça definida (idade e peso corporal médios de seis anos e $340 \mathrm{~kg}$ ) foram utilizados em um delineamento em blocos casualizados, que continham quatro repetições. Cada cavalo foi utilizado para originar os dados referentes a todos os tratamentos, ou seja, à coleta total de fezes e às técnicas in vitro, para obtenção dos indicadores (fibras em detergente neutro e ácido indigestíveis). Assim, cada animal foi considerado um bloco, o que totalizou quatro repetições (ÍTAVO et al., 2002).

Os tratamentos consistiram de metodologias de avaliação de digestibilidade, constituídos por método direto com a coleta total de fezes, e indireto pelo uso de indicadores internos, fibras em detergente neutro e ácido indigestíveis, obtidos pelas técnica in vitro, por meio dos inóculos, líquido ruminal e fezes equina, perfazendo cinco tratamentos. Desta forma, o primeiro ensaio foi constituído por equinos que consumiram exclusivamente feno de coast-cross e, para o ensaio 2, os animais receberam $70 \%$ de feno de coast-cross e $30 \%$ de grãos de milho, todos com fornecimento de sal mineral ad libitum.

A quantidade de alimento fornecida aos cavalos foi estabelecida, segundo as recomendações do National Research Council (NRC, 1989), com a finalidade de atender às exigências nutricionais para a categoria. A ingestão diária de MS foi de $2,0 \%$ do peso corporal. As refeições foram fornecidas diariamente, às $08 \mathrm{~h}, 12 \mathrm{~h}$ e $17 \mathrm{~h}$, e as sobras foram retiradas e pesadas 15 minutos antes de cada refeição, cujas composições químicas do feno e milho, utilizados nos ensaios 1 e 2 , encontram-se na Tabela 1.

Tabela 1.Composição química dos alimentos ${ }^{1}$

\begin{tabular}{|c|c|c|c|c|c|c|}
\hline \multirow{2}{*}{ Alimento } & \multirow{2}{*}{ MS (\%) } & \multicolumn{5}{|c|}{ Nutriente (\% MS) } \\
\hline & & $\mathrm{MO}$ & Amido & PB & FDN & FDA \\
\hline Feno de coast-cross & 91,20 & 95,21 & 2,59 & 7,47 & 80,70 & 42,79 \\
\hline Milho em grão & 88,25 & 98,45 & 63,59 & 8,99 & 20,25 & 5,34 \\
\hline
\end{tabular}

A pesquisa teve a duração total de 32 dias, para cada ensaio de digestão, divididos em duas fases experimentais e constituídos por 20 dias para a fase I (coleta total de fezes, ou seja, método direto) e 12 dias na fase II (avaliação das metodologias indiretas).
A fase I foi destinada para determinação da digestibilidade pelo método direto, no qual os primeiros 15 dias foram utilizados para a adaptação dos animais às instalações, às dietas e às condições de manejo. Os animais ficaram alojados em baias individuais que mediam, $2 \times 3 \mathrm{~m}$, 
Rev. Bras. Saúde Prod. Anim., Salvador, v.13, n.2, p.410-423 abr./jun., 2012 http://www.rbspa.ufba.br ISSN 15199940

com piso de cimento, sem cama, com comedouro para ração e sal e bebedouro tipo "balde". Após este período, os cavalos foram colocados em gaiolas de metabolismo, providas de baldes plásticos para água e sal mineral, comedouro frontal e coletor de fezes, por meio do qual se procedeu a coleta total por cinco dias.

As coletas de fezes foram realizadas quatro vezes ao dia (seis; $12 ; 18$ e 24 horas), pesadas, homogeneizadas e amostradas em 10\%. Essas amostras foram colocadas em sacos plásticos, identificados e armazenados a uma temperatura de $-15^{\circ} \mathrm{C}$, para posteriores análises (ARAÚJO et al., 2003; SIQUEIRA et al., 2009). Antes do início do experimento, foi administrado aos cavalos vermífugo de amplo espectro, que continha como princípio ativo moxidectina,

Ao final da fase I, as amostras de fezes foram descongeladas à temperatura ambiente, homogeneizadas por tratamento para obtenção de uma amostra composta para cada animal, das quais foram retiradas alíquotas de $10 \%$, pesadas e pré-secas em estufa de ventilação de ar forçada à $60^{\circ} \mathrm{C}$, por 72 horas. Após a secagem procedeu-se uma nova pesagem e, em seguida, a moagem em peneira com crivo de $1 \mathrm{~mm}$.

As análises bromatológicas (MS, MO e PB) do feno, milho e fezes foram feitas segundo a metodologia descrita por Silva \& Queiroz (2002), e os componentes da parede celular (FDN e FDA) segundo Campos et al. (2004), no Laboratório de Nutrição Animal da Faculdade de Medicina Veterinária e Zootecnia UNESP - Campus de Botucatu. A determinação de amido foi realizada de acordo com Macrae \& Armstrong (1968), no Laboratório de Bromatologia pertencente ao Departamento de Zootecnia da ESALQ/USP.

A fase II do experimento foi conduzida no intuito de mensurar as metodologias indiretas, as quais foram compostas por seis dias para cada uma das técnicas in vitro com os inóculos, líquido ruminal e fezes equina. $\mathrm{O}$ sistema de fermentação in vitro utilizado foi o Tilley \& Terry (1963), no qual a pepsina-HCL foi substituída pelas extrações de FDN, modificado por Goering \& Van Soest (1970), e de FDA conforme Waller et al. (1980), aplicadas aos resíduos após digestão microbiana.

As amostras moídas a $1 \mathrm{~mm}$ de feno, milho e fezes (dos cavalos da fase anterior) foram pesadas em quadruplicatas, para cada uma das técnicas in vitro, em tubos de ensaio de $100 \mathrm{~mL}$ e incubadas com líquido ruminal ou fezes equina. Desta maneira, procedeuse o monitoramento do $\mathrm{pH}$ no material incubado, por meio de potenciômetro digital DIGIMED ${ }^{\circledR}$ e corrigido para 6,8 , quando necessário, nas primeiras oito horas após a incubação, em intervalos de quatro horas, bem como os tubos foram agitados manualmente a cada três horas até completar 48 horas (CAMPOS et al., 2004). Posteriormente, a agitação foi realizada duas vezes por dia até completar as 144 horas (El SHAER et al., 1987; MORAIS et al., 2010). Após o período de incubação foi interrompida a fermentação com adição de tolueno e, em seguida, foram determinados os indicadores indigestíveis, fibra em detergentes neutro e ácido.

Utilizou-se uma vaca Holandesa, portadora de cânula ruminal, com peso corporal de $450 \mathrm{~kg}$, como doadora de inóculo microbiano, em que a quantidade de alimento fornecida foi estabelecida, segundo as recomendações National Research Council (NRC, 2001), para 
vacas com produção potencial de $30 \mathrm{~kg}$ de leite/dia. Esse animal permaneceu em lote de produção de leite, consumindo pasto de capim-tanzânia ad libitum e suplementada com $40 \%$ de concentrado. Assim, o líquido ruminal foi coletado antes da primeira refeição do dia, via cânula localizada no rúmen, filtrado e transferido para garrafa térmica, onde foi feito o borbulhamento com dióxido de carbono $\left(\mathrm{CO}_{2}\right)$ para manter as condições anaeróbicas. Em seguida, nos tubos de ensaio contendo $0,5 \mathrm{~g}$ de amostra, adicionaram-se $10 \mathrm{~mL}$ de solução tampão, $12 \mathrm{~mL}$ de líquido ruminal, borbulhados com $\mathrm{CO}_{2}$, lacrados e colocados em banho-maria a $39^{\circ} \mathrm{C}$ (CAMPOS et al., 2004).

Para a técnica in vitro por meio de inóculo das fezes equinas, o material foi obtido de um cavalo castrado, que consumia feno de coast-cross, sem raça definida e peso corporal de $400 \mathrm{~kg}$ para atender às exigências de mantença conforme $\mathrm{o}$ National Research Council (NRC, 1989). Assim, as fezes foram colhidas diretamente do reto do animal, antes da primeira refeição do dia e acondicionadas em bolsa térmica e levadas ao laboratório. Nesse local, as fezes equinas foram misturadas com saliva artificial, aquecida a $39^{\circ} \mathrm{C}$ (MCDOUGALL, 1948) em liquidificador, na proporção de $1: 1$, com base no peso in natura e borbulhadas com $\mathrm{CO}_{2}$ (El SHAERet al., 1987), o que originou a mistura fecal. Essa mistura foi filtrada em camada dupla de "pano de queijo" e diluída novamente com saliva artificial para obtenção de uma solução fecal a 3\%. A essa solução fecal foi acrescentada solução de ureia a 3\%, na proporção de 3:100 (solução de ureia: solução fecal), o que resultou na solução fecal diluída, na qual novamente foi injetado $\mathrm{CO}_{2}$ por cinco minutos. Portanto, essa solução fecal diluída foi obtida ao adicionar-se, a um becker de 2 litros, $30 \mathrm{~mL}$ da mistura fecal, $1000 \mathrm{~mL}$ de saliva artificial e $30 \mathrm{~mL}$ de solução de ureia a 3\%. Após esses procedimentos, acrescentou-se $12 \mathrm{~mL}$ de solução fecal diluída mais $10 \mathrm{~mL}$ de saliva artificial aos tubos de ensaio contendo $0,5 \mathrm{~g}$ de amostra, borbulhados com $\mathrm{CO}_{2}$, lacrados e colocados em banho-maria a $39^{\circ} \mathrm{C}$.

Os coeficientes de digestibilidade da MS (CDMS) e dos nutrientes (CDN) foram estimados e baseados nas seguintes equações (OLIVEIRA et al., 2007):

$$
\begin{gathered}
\operatorname{CDMS}(\%)=\quad 100-\left(100 \times \frac{\% \text { Indicador na Dieta }}{\% \text { Indicador nas Fezes }}\right) \\
\operatorname{CDN~}(\%)=\quad 100-\left(100 \times \frac{\% \text { Indicador na Dieta }}{\% \text { Indicador nas Fezes }} \times \frac{\% \text { Nutriente nas Fezes }}{\% \text { Nutriente na Dieta }}\right)
\end{gathered}
$$

A taxa de recuperação (TR) dos indicadores foi determinada, conforme Zeoula et al. (2002) pela seguinte equação:

$$
\mathrm{TR}(\%)=\frac{\% \text { Indicador nas Fezes x Produção Fecal Observada }(\mathrm{g})}{\text { Indicador Ingerido }(\mathrm{g})} \times 100
$$


Rev. Bras. Saúde Prod. Anim., Salvador, v.13, n.2, p.410-423 abr./jun., 2012 http://www.rbspa.ufba.br ISSN 15199940

Os coeficientes de digestibilidade dos nutrientes, alcançados pelo método direto e indireto, com a obtenção de indicadores indigestíveis por meio da técnica in vitro, que, por sua vez, continha como inóculos líquido ruminal e fezes equina oriundos dos ensaios de digestão, foram submetidos à análise de variância do Statistical Analysis System (SAS INSTITUTE, 2000). A comparação entre médias foi realizada pelo teste Tukey, a $5 \%$ de significância.

\section{RESULTADOS E DISCUSSÃO}

A concentração dos indicadores indigestíveis presentes no feno de coastcross apresentou variações significativas quanto ao inóculo utilizado na metodologia de obtenção in vitro, líquido ruminal $\mathrm{x}$ fezes equina, o que demonstra a necessidade de maior padronização dessas técnicas usadas na experimentação de cavalos (Tabela 2).

Tabela 2. Concentração (\% na MS), consumo (g/d) e a taxa de recuperação (\%) dos indicadores indigestíveis obtidos in vitro, usando diferentes inóculos para equinos alimentados com feno de coast-cross ${ }^{1}$

\begin{tabular}{|c|c|c|c|c|c|c|}
\hline \multirow{3}{*}{ Variável } & \multirow{3}{*}{$\mathrm{CT}^{1}$} & \multicolumn{4}{|c|}{ Inóculo } & \multirow{3}{*}{$\mathrm{CV}(\%)$} \\
\hline & & \multicolumn{2}{|c|}{ Líquido Ruminal } & \multicolumn{2}{|c|}{ Fezes Equina } & \\
\hline & & $\mathrm{FDNi}^{2}$ & $\mathrm{FDAi}^{3}$ & FDNi & FDAi & \\
\hline Concentração & - & $38,36^{\mathrm{a}}$ & $20,97^{\mathrm{c}}$ & $38,22^{b}$ & $20,52^{d}$ & 0,10 \\
\hline Consumo & - & $210,31^{\mathrm{a}}$ & $114,97^{\mathrm{c}}$ & $209,54^{\mathrm{b}}$ & $112,50^{\mathrm{d}}$ & 0,10 \\
\hline Taxa Recuperação & $100^{\mathrm{a}}$ & $83,43^{\mathrm{c}}$ & $88,28^{\mathrm{b}}$ & $94,08^{b}$ & $103,67^{\mathrm{a}}$ & 3,39 \\
\hline
\end{tabular}

${ }^{1} \mathrm{CT}=$ Coleta total de fezes; ${ }^{2} \mathrm{FDNi}=$ Fibra em detergente neutro indigestível; ${ }^{3} \mathrm{FDAi}=$ Fibra em detergente ácido indigestível; Médias com letras diferentes na mesma linha diferem $(\mathrm{P}<0,05)$ entre si pelo teste Tukey.

O teor de fibra em detergente ácido indigestível médio de $20,8 \%$ foi inferior aos valores médios observados, ao utilizar incubações in vitro em líquido ruminal, por Berchielli et al. (2005), que foi de $24,36 \%$ para o feno de Tifton e de $23,56 \%$ para o feno de coast-cross (STEIN et al., 2006). Assim, evidenciou-se mais uma vez a falta de homogeneidade dos métodos de análise, que de acordo com Detmann et al. (2001), Ferreira et al. (2009) e Silva et al. (2009), são os principais responsáveis por estas divergências de resultados entre pesquisas. Diferentemente, a percentagem média da fibra em detergente neutro indigestível de $38,3 \%$ do atual ensaio superou os valores verificados para os fenos de Bermuda e do Tifton, obtidos in vitro com líquido ruminal, de 31,7 e $32,06 \%$, respectivamente (LIPPKE et al., 1986; BERCHIELLI et al., 2005).

A característica de maior importância de um indicador ideal baseia-se em sua capacidade de resistir à digestão durante a exposição pelo trato gastrointestinal (FAICHNEY, 1975, ZEOULA et al., 2002; BRITO et al., 2007). Dessa forma, a análise da taxa de recuperação fecal dos indicadores demonstrou ocorrer digestão nula para fibra em detergente ácido indigestível, em inóculo com fezes equina, por ter promovido a melhor 
recuperação fecal, igualando-se ao grupo controle em 103,67\% $(\mathrm{P}>0,05)$. Essa relativa indigestibilidade da fibra em detergente ácido indigestível, em fezes equina, para cavalos que consumiam feno de coast-cross, confere grande capacidade em predizer acuradamente a digestibilidade a esse indicador.

Em contrapartida, as determinações das fibras em detergente neutro e ácido indigestíveis em líquido ruminal resultaram nas piores taxa de recuperação com média de 85,85\% (Tabela 2), o que denota significante desaparecimento desses indicadores durante $\mathrm{o}$ trânsito gastrintestinal. Ainda assim, essa taxa foi inferior ao verificado na literatura para diferentes volumosos na alimentação de ruminantes, em que se utilizou da técnica in vitro em líquido ruminal, o que resultou nos valores entre 90,8 - 94,1\% para fibra em detergente neutro indigestível e 87,7 $89,6 \%$ para fibra em detergente ácido indigestível (LIPPKE et al., 1986; MAEDA et al., 2011). Essa inabilidade da técnica com líquido ruminal, como inóculo na incubação in vitro, em recuperar quantitativamente a fibra em detergente neutro indigestível e fibra em detergente ácido indigestível demonstra sua fragilidade em predizer a digestibilidade aparente de nutrientes do feno de coast-cross quando fornecido exclusivamente na alimentação de equinos.

Tabela 3. Coeficientes de digestibilidade aparente (CD) da matéria seca (MS), matéria orgânica (MO), proteína bruta (PB) e fibra em detergente neutro (FDN) do feno de coast-cross obtidos em diferentes metodologias na alimentação de equinos $(\% \text { na MS })^{1}$

\begin{tabular}{|c|c|c|c|c|c|c|}
\hline \multirow{3}{*}{ Variável } & \multicolumn{5}{|c|}{ Metodologia } & \multirow{3}{*}{ CV $(\%)$} \\
\hline & \multirow{2}{*}{$\mathrm{CT}^{1}$} & \multicolumn{2}{|c|}{ "in vitro" - LR ${ }^{2}$} & \multicolumn{2}{|c|}{ "in vitro" $-\mathrm{FE}^{3}$} & \\
\hline & & $\mathrm{FDNi}^{4}$ & FDAi $^{5}$ & FDNi & FDAi & \\
\hline CDMS & $46,41^{\mathrm{a}}$ & $35,72^{b}$ & $39,25^{b}$ & $43,04^{\mathrm{a}}$ & $48,20^{\mathrm{a}}$ & 4,35 \\
\hline CDMO & $48,16^{\mathrm{a}}$ & $37,82^{\mathrm{b}}$ & $41,24^{\mathrm{b}}$ & $44,90^{\mathrm{a}}$ & $49,90^{\mathrm{a}}$ & 4,03 \\
\hline CDPB & $46,90^{\mathrm{a}}$ & $36,36^{\mathrm{b}}$ & $39,85^{b}$ & $43,50^{\mathrm{a}}$ & $48,71^{\mathrm{a}}$ & 4,11 \\
\hline CDFDN & $47,92^{\mathrm{a}}$ & $37,53^{b}$ & $40,94^{b}$ & $44,66^{\mathrm{a}}$ & $49,66^{\mathrm{a}}$ & 4,14 \\
\hline
\end{tabular}

${ }^{1} \mathrm{CT}=$ Coleta total de fezes $;{ }^{2} \mathrm{LR}=$ Líquido ruminal; ${ }^{3} \mathrm{FE}=$ Fezes equina; ${ }^{4} \mathrm{FDNi}=$ Fibra em detergente neutro indigestível; ${ }^{5}$ FDAi $=$ Fibra em detergente ácido indigestível; Médias com letras diferentes na mesma linha diferem $(\mathrm{P}<0,05)$ entre si pelo teste Tukey.

Os CD da MS, MO, PB e FDN determinados pela coleta total de fezes e estimados pela fibra em detergente neutro indigestível e fibra em detergente ácido indigestível em fezes equina foram similares $(\mathrm{P}>0,05)$, porém apresentaram diferenças significativas aos resultados obtidos pelo uso da fibra em detergente neutro indigestível e fibra em detergente ácido indigestível em líquido ruminal, e subestimou a digestibilidade dos nutrientes. Dessa forma, as estimativas dos coeficientes de digestibilidade dos nutrientes foram adequadamente preditos pela fibra em detergente neutro indigestível e fibra em detergente ácido indigestível, obtidas por meio das fezes equina como inóculo, no qual os valores 
Rev. Bras. Saúde Prod. Anim., Salvador, v.13, n.2, p.410-423 abr./jun., 2012 http://www.rbspa.ufba.br ISSN 15199940

observados foram de 46,41; 48,16; 46,90; $47,92 \%$ para $\mathrm{MS}, \mathrm{MO}, \mathrm{PB}$ e FDN, respectivamente.

Resultados conflitantes foram verificados por Stein et al. (2006) nos quais a estimativa dos CDMS de cavalos alimentados com feno de coast-cross foi predito acuradamente e com precisão pela fibra em detergente ácido indigestível, obtida in vitro em líquido ruminal. Oliveira et al. (2003), ao trabalharem com equinos e com o mesmo feno, observaram superestimativa da digestibilidade da MS, FDN e FDA como consequência da utilização da fibra em detergente neutro indigestível e fibra em detergente ácido indigestível, em líquido ruminal, diferentemente ao observado na atual pesquisa.

No segundo ensaio, verificou-se também efeito significativo, quanto ao inóculo utilizado na metodologia de obtenção in vitro, líquido ruminal $\mathrm{x}$ fezes equina, na determinação dos indicadores, fibra em detergente neutro indigestível e fibra em detergente ácido indigestível, para cavalos que consumiam dieta mista constituída por $70 \%$ de feno de coast-cross e $30 \%$ de grãos de milho (Tabela 4). Contudo, não se verificou efeito significativo do tipo de indicador, bem como do inóculo utilizado na obtenção dos indicadores, na taxa de recuperação fecal, no qual o valor médio foi de $101,71 \%(\mathrm{P}>0,05)$.

Tabela 4. Concentração (\% na MS), consumo (g/d) e a taxa de recuperação (\%) dos indicadores indigestíveis obtidos "in vitro" usando diferentes inóculos para equinos alimentados com feno de coast-cross mais grãos de milho ${ }^{1}$

\begin{tabular}{|c|c|c|c|c|c|c|}
\hline \multirow{3}{*}{ Variável } & \multirow{3}{*}{$\mathrm{CT}^{1}$} & \multicolumn{4}{|c|}{ Inóculo } & \multirow{3}{*}{$\mathrm{CV}(\%)$} \\
\hline & & \multicolumn{2}{|c|}{ Líquido Ruminal } & \multicolumn{2}{|c|}{ Fezes Equina } & \\
\hline & & $\mathrm{FDNi}^{2}$ & $\mathrm{FDAi}^{3}$ & FDNi & FDAi & \\
\hline Concentração & - & $17,35^{\mathrm{b}}$ & $10,55^{\mathrm{d}}$ & $23,54^{\mathrm{a}}$ & $14,09^{c}$ & 1,28 \\
\hline Consumo & - & $102,22^{b}$ & $62,11^{\mathrm{d}}$ & $138,82^{\mathrm{a}}$ & $83,26^{\mathrm{c}}$ & 2,75 \\
\hline Taxa Recuperação & 100 & 100,38 & 99,92 & 102,86 & 103,67 & 3,46 \\
\hline
\end{tabular}

Essa ocorrência de digestão praticamente nula da fibra em detergente neutro indigestível e fibra em detergente ácido indigestível, durante o trânsito gastrintestinal, depõem favoravelmente a esses indicadores como possuidores de grande capacidade em predizer acuradamente a digestibilidade de nutrientes em equinos alimentados com dieta mista.
Semelhantemente, Stein et al. (2006), ao avaliarem a fibra em detergente ácido indigestível, celulose indigestível e lignina como indicadores na alimentação de éguas alimentadas com dieta mista, obtiveram recuperação fecal igual a $100 \%$ $(\mathrm{P}<0,05)$ para a fibra em detergente ácido indigestível, obtida em incubação in vitro com líquido ruminal.

Resultados contraditórios foram verificados na experimentação de cavalos quanto à 
eficiência da recuperação destes indicadores, em que Oliveira et al. (2003), verificaram taxas de recuperação positivas de 118,37 e $122,88 \%$ para fibra em detergente neutro indigestível e fibra em detergente ácido indigestível, respectivamente, obtidos por incubação in vitro com líquido ruminal, em equinos que consumiam dieta mista, na proporção de 60:40 de volumoso:concentrado. Quanto a isso, a literatura sugere a ocorrência do aumento de resíduo após incubação in vitro, superestimando a quantidade do indicador na amostra, como consequência de partículas que se aderem à parede e tampa do tubo (FREITAS et al., 2002). Ainda assim, Vasconcellos et al., (2007), consideram que essas recuperações positivas devem-se à ligação de monômeros fenólicos livres com os componentes da dieta de baixo peso molecular, o que aumenta a contribuição da fração lignina nas fezes.

Vale ressaltar, que além da possibilidade de haver indicador específico para cada tipo de volumoso (BERCHIELLI et al., 2005 e SILVA et al., 2010), ainda deve-se atentar ao tipo de alimentação do animal. Dessa forma, o tipo de dieta, exclusiva com volumoso ou mista, interfere na taxa de recuperação fecal dos indicadores, $\mathrm{o}$ que pode, então, recomendar a fibra em detergente ácido indigestível para alimentação constituída somente de volumoso e fibra em detergente neutro indigestível e fibra em detergente ácido indigestível, para dieta mista na experimentação de equinos.

As estimativas dos coeficientes de digestibilidade dos nutrientes foram adequadamente preditos pela fibra em detergente ácido indigestível, obtida por meio de ambos inóculos e fibra em detergente neutro indigestível em fezes equina $(\mathrm{P}<0,05)$, para equinos alimentados com dieta mista, conforme a tabela 5 , na qual os valores médios observados foram de $52,63,54,17,64,90,43,73$ e $98,28 \%$ para MS, MO, PB, FDN e Amido, respectivamente.

Tabela 5. Coeficientes de digestibilidade aparente (CD) da matéria seca (MS), matéria orgânica (MO), proteína bruta (PB), fibra em detergente neutro (FDN) e amido obtidos em diferentes metodologias para equinos alimentados com feno de coast-cross mais grãos de milho (\% na MS $)^{1}$

\begin{tabular}{|c|c|c|c|c|c|c|}
\hline \multirow{3}{*}{ Variável } & \multicolumn{5}{|c|}{ Metodologia } & \multirow{3}{*}{$\mathrm{CV}(\%)$} \\
\hline & \multirow{2}{*}{$\mathrm{CT}^{1}$} & \multicolumn{2}{|c|}{ "in vitro" - LR ${ }^{2}$} & \multicolumn{2}{|c|}{ "in vitro" $-\mathrm{FE}^{3}$} & \\
\hline & & $\mathrm{FDNi}^{4}$ & $\mathrm{FDAi}^{5}$ & FDNi & FDAi & \\
\hline CDMS & $52,63^{\mathrm{a}}$ & $48,37^{b}$ & $53,09^{a}$ & $50,16^{\mathrm{a}}$ & $53,04^{\mathrm{a}}$ & 3,98 \\
\hline CDMO & $54,17^{\mathrm{a}}$ & $50,53^{\mathrm{a}}$ & $55,05^{\mathrm{a}}$ & $52,24^{\mathrm{a}}$ & $55,00^{\mathrm{a}}$ & 3,86 \\
\hline CDPB & $64,90^{\mathrm{a}}$ & $61,73^{b}$ & $65,23^{\mathrm{a}}$ & $63,04^{\mathrm{a}}$ & $65,19^{\mathrm{a}}$ & 3,11 \\
\hline CDFDN & $43,73^{\mathrm{a}}$ & $38,74^{\mathrm{b}}$ & $44,31^{\mathrm{a}}$ & $40,79^{\mathrm{a}}$ & $44,26^{\mathrm{a}}$ & 5,76 \\
\hline CDAmido & $98,28^{\mathrm{a}}$ & $98,14^{\mathrm{a}}$ & $98,32^{\mathrm{a}}$ & $98,21^{\mathrm{a}}$ & $98,32^{\mathrm{a}}$ & 0,08 \\
\hline
\end{tabular}

${ }^{\mathrm{T}} \mathrm{CT}=$ Coleta total de fezes; ${ }^{2} \mathrm{LR}=$ Líquido ruminal; ${ }^{3} \mathrm{FE}=$ Fezes equina; ${ }^{4} \mathrm{FDNi}=$ Fibra em detergente neutro indigestível; ${ }^{5}$ FDAi $=$ Fibra em detergente ácido indigestível; Médias com letras diferentes na mesma linha diferem $(\mathrm{P}<0,05)$ entre si pelo teste Tukey. 
Rev. Bras. Saúde Prod. Anim., Salvador, v.13, n.2, p.410-423 abr./jun., 2012 http://www.rbspa.ufba.br ISSN 15199940

De maneira conflitante, Oliveira et al. (2003), verificaram superestimativa dos CD da MS, EB, FDN e FDA, em comparação ao método convencional, obtidos por incubação in vitro em líquido ruminal para potros alimentados com diferentes relações de concentrado e volumoso. Portanto, a obtenção de indicadores indigestíveis por meio da técnica in vitro, que utiliza como inóculo fezes equina, é promissora na predição da produção fecal, bem como no processo de avaliação do valor nutritivo de alimentos na experimentação de cavalos.

A análise dos dados nos permite concluir que as fezes equinas podem ser utilizadas como inóculo em substituição ao líquido ruminal, na obtenção dos indicadores indigestíveis por meio de incubação in vitro, o que a torna uma técnica promissora na experimentação em cavalos. Adicionalmente, as fibras indigestíveis em detergente neutro e ácido, mediante o uso de fezes equina como inóculo, apresentaram-se como os melhores indicadores para estimar os coeficientes de digestibilidade da MS, MO, PB, FDN e amido para equinos alimentados exclusivamente com feno de coast-cross e com dieta mista.

O líquido ruminal utilizado na incubação in vitro para obtenção dos indicadores apresentou baixa taxa de recuperação fecal e, consequentemente, digestibilidade aparente de nutrientes subestimadas para o feno e feno e mais grãos na alimentação dessa espécie animal.

\section{REFERÊNCIAS}

\begin{abstract}
ABDOULI, H.; BEN ATTIA, S. Evaluation of a two-stage in vitro technique for estimating digestibility of equine feeds using horse faeces as the source of microbial inoculums. Animal Feed Science and Technology, v.132, p.155-162, 2007.
\end{abstract}

ALMEIDA, F.Q.; SILVA, V.P. Progresso científico em equideocultura na la década do século XXI. Revista Brasileira de Zootecnia, v.39, p.119129, 2010. Supl.

ARAÚJO, K.V.; LIMA, J.A.F.; FIALHO, E.T.; FRANCO, G.L.

Avaliação de períodos de coleta total de fezes para determinar a digestibilidade aparente dos nutrientes em equinos.

Ciência Agrotécnica, v.27, n.4, p.886893, 2003.

BERCHIELLI, T.T.; OLIVEIRA, S.G.; CARRILHO, E.N.V.M.; FEITOSA, J.V.; LOPES, A.D. Comparação de marcadores para estimativas de produção fecal e de fluxo de digesta em bovinos. Revista Brasileira de

Zootecnia, v.34, n.3, p.987-996, 2005.

BERGERO, D.; MEINERI, G.;

MIRAGLIA, N.; GIORGIO PEIRETTI, P. Apparent digestibility of hays in horses determined by total collection of faeces and using internal marker methods. International Journal of Food, Agriculture and Environment, v.3, n.1, p.199-202, 2005. 
Rev. Bras. Saúde Prod. Anim., Salvador, v.13, n.2, p.410-423 abr./jun., 2012 http://www.rbspa.ufba.br ISSN 15199940

BRITO, R.M.; SAMPAIO, A.A.M.; RESENDE, K.T.; FERNANDES, A.R.M.; HENRIQUE, W.; ROUTMAN, K.S.

Avaliação de indicadores para estimativa das digestibilidades parciais e total de dietas em bovinos. Revista Brasileira de

Zootecnia, v.36, n.2, p.445-451, 2007.

CAMPOS, F.P.; NUSSIO, C.M.B.; NUSSIO, L.G. Métodos de análises de alimentos. Piracicaba: FEALQ, 2004. $135 \mathrm{p}$.

DETMANN, E.; PAULINO, M.F.; ZERVOUDAKIS, J.T; VALADARES FILHO, S.C.; EUCLYDES, R.F.; LANA, R.P.; QUEIROZ, D.S. Cromo e indicadores internos na determinação do consumo de novilhos mestiços, suplementados, a pasto.

Revista Brasileira de Zootecnia, v.30, n.5, p.1600-1609, 2001.

EARING, J.E.; CASSILL, B. D.; HAYES, S. H.; VANZANT, E. S.; LAWRENCE L. $M$. Comparison of in vitro digestibility estimates using the Daisy ${ }^{\text {II }}$ incubator with in vivo digestibility estimates in horses. Jounal Animal Science, v. 12, n. 88, p.3954-3963, 2010.

EL SHAER, H.M.; OMED, H.M.; CHAMBERLAIN, A.G. Use of faecal organisms from sheep for the "in vitro" determination of digestibility. Journal of Agriculture Science, v.109, p.257-259, 1987.

FAICHNEY, G.J. The use of markers to partition digestion within the gastrointestinal tract of ruminants. In: MACDONALD, I.W.; WARNER A.C.I. (Eds.). Digestion and metabolism in the ruminant. Austrália: Univ. of New England Publishing Unit, 1975. p.277-291.
FERREIRA, M.A.; VALADARES FILHO, S.C.; MARCONDES, M.I.; PAIXÃO, M.L.; PAULINO, M.F.; VALADARES, R.F.D. Avaliação de indicadores em estudos com ruminantes: digestibilidade. Revista Brasileira de Zootecnia, v.38, n.8, p.1568-1573, 2009.

FREITAS, D.; BERCHIELLI, T.T.; SILVEIRA, R.N.; SOARES, J.P.G.; FERNANDES, J.J.R.; PIRES, A.V. Produção fecal e fluxo duodenal da matéria seca e matéria orgânica estimados por meio de indicadores.

Revista Brasileira de Zootecnia, v.31, n.3, p.1525-1530, 2002.

GOERING, H.K.; VAN SOEST, P.J. Forage fiber analysis (Apparatus, reagents, procedures and some applications). Washington, DC: USDA, 1970. (Agricultural Handbook, 379).

ÍTAVO, L.C.V.; VALADARES FILHO, S.C.; SILVA, F.F.; VALADARES, R.F.D.; PAULINO, M.F.; ÍTAVO, C.C.B.F.; MORAES, E.H.B.K. Comparação de indicadores e metodologia de coleta para estimativas de produção fecal e fluxo de digesta em bovinos. Revista Brasileira de Zootecnia, v.31, n.4, p.1833-1839, 2002.

LATTIMER, J.M.; COOPER, S.R.; FREEMAN, D.W.; LALMAN, D.L. Effect of yeast culture on in vitro fermentation of a high-concentrate or high-fiber diet using equine fecal inoculum in a Daisy II incubator. Journal Animal Science, v. 25, n.5, p.655-683, 2007. 
Rev. Bras. Saúde Prod. Anim., Salvador, v.13, n.2, p.410-423 abr./jun., 2012 http://www.rbspa.ufba.br ISSN 15199940

LAUDADIO, V.; LACALANDRA G.M.; MONACO D.; KHORCHANI T.; HAMMADI M.; TUFARELLI V. Faecal liquor as alternative microbial inoculum source for in vitro (DaisyII) technique to estimate the digestibility of feeds for camels. Journal of Camelid Science, v.2, n.1, p.1-7, 2009.

LIPPKE, H. Estimation of forage intake by ruminants on pasture. Crop Science, v.42, n.3, p.869-872, 2002.

LIPPKE, H.; ELLIS, W.C.; JACOBS, B.F. Recovery of indigestible fiber from feces of sheep and cattle on forage diets. Journal of Dairy Science, v.69, n.2, p.403-412, 1986.

MACRAE, J.C.; ARMSTRONG, D.G. Enzyme method for determination of linked glucose polymers in biological materials.

Journal of Science Agriculture, v.19, p.578-581, 1968.

MAEDA, E.M.; ZEOULA, L.M.; GOMES H.C.C.; JACOBI, G.; SIMIONI, F.L.; OLIVEIRA, R.A. Avaliação de indicadores usados nos estudos de ingestão e digestibilidade em bovinos e bubalinos.

Archivos de Zootecnia, v.60; n.229, p.123-131, 2011.

MCDOUGALL, E.I. Studies on ruminant saliva. I. Composition and output of sheep saliva. Biochemistry Journal, v.43, p.99109, 1948.

MORAIS, J.A.S.; BERCHIELLI, T.T.; OLIVEIRA, S.G.; QUEIROZ, M.F.S.; TORO-VELÁSQUEZ, P.A.; RIVERARIVERA, A. Diferentes procedimentos na determinação de indicadores internos para estimativa de produção fecal e fluxo duodenal de materia seca em bovinos. Acta scientiarum. Animal sciences, v.32, n.2, p.213-218, 2010.
NATIONAL RESEARCH COUNCIL NRC. Nutrient requirements of

horses. 5.rev.ed. Washington: National Academy of Sciences, 1989. 100p.

NATIONAL RESEARCH COUNCIL NRC. Nutrient requirements of dairy cattle. 7.rev.ed. Washington, D.C.:

2001. 381p.

OLIVEIRA, C.A.A.; ALMEIDA, F.Q.; VALADARES FILHO, S.C.; VIEIRA, A.A.; ALMEIDA, M.I.V.; CORASSA, A.; LOPES, B.A.; MACEDO, R.

Estimativa da digestibilidade aparente de nutrientes em dietas para eqüinos, com o uso de oxido crômico e indicadores internos. Revista Brasileira de Zootecnia, v.32, n.6, p.1681-1689, 2003. Supl. 1.

OLIVEIRA JÚNIOR, R.C.; PIRES, A.V.; FERNANDES, J.J.R.; SUSIN, I.; SANTOS, F.A.P.; NASCIMENTO FILHO, V.F.; ARAÚJO, R.C. Avaliação de indicadores para estimar a digestibilidade dos nutrientes em novilhos nelore alimentados com dietas contendo alto teor de concentrado e fontes nitrogenadas. Revista Brasileira de Zootecnia, v.33, n.3, p.749-758, 2004.

OLIVEIRA, K.; COSTA, C.; FAUSTINO, M.G.; SANTOS, V.P.; LIMA, M.N.; FILHO, V.F.N.;

ABDALLA, A.L. Valor nutritivo e estudo cinético do trato digestivo de dietas contendo grãos secos ou silagem de grãos úmidos de sorgo de baixo e alto tanino para equinos. Revista Brasileira de Zootecnia, v.36, n.6, p.1809-1819, 2007. 
Rev. Bras. Saúde Prod. Anim., Salvador, v.13, n.2, p.410-423 abr./jun., 2012 http://www.rbspa.ufba.br ISSN 15199940

PATTERSON, D.P.; COOPER, S.R.; FREEMAN, D.W.; TEETER, R.G. TECHNICAL NOTE: Estimation of fecal output and dry matter digestibility using various chromic oxide marker methods in the horse. Professional Animal Scientist, v.18, n.2, p.176-179, 2002.

SILVA, D.J.; QUEIROZ, A.C. Análise de alimentos: métodos químicos e biológicos. 3.ed. Viçosa, MG:

Universidade Federal de Viçosa, 2002, $235 \mathrm{p}$.

SILVA, F.F.; AGUIAR, M.S.M.A.; VELOSO, C.M.; PIRES, A.J.V.; BONOMO, P.; ALMEIDA, V.S.; SILVA, R.R.; CARVALHO, G.G.P.; MARQUES, J.A., DIAS, A.M.; ÍTAVO, L.C.V.

Produção fecal e digestibilidade estimada por indicadores internos comparados a coleta total. Archivos de zootecnia, v.58, n.224, p.741-744, 2009.

SILVA, J.J.; SALIBA, E.O.S.; BORGES, I.; GONÇALVES, L.C.; RODRIGUÉZ, N.M.; AROEIRA, L.J.M.; SILVA, A.G.M.; COSTA, F.J.N. Indicadores para estimativa de consumo total por novilhas holandês x zebu mantidas em confinamento. Revista Brasileira de Saúde e Produção Animal, v.11, n.3, p.838-848, 2010.

SILVA, K.T.; SILVA, D.C.; SANTOS, G.T.; ALCALDE, C.R.; ZAMBOM, M.A.; MODESTO, E.C.; FURTADO, C.E. Utilização de fezes (equina e bovina) em substituição ao líquido ruminal como fonte de inóculo para determinação da digestibilidade "in vitro" de alimentos para ruminantes. Acta Scientiarum, v.25, n.2, p.355-361, 2003.
SIQUEIRA, R.F.; GOMES, R.C; RODRIGUES, P.H.M.; FUKUSHIMA, R.S.; LORENZO, C.L.F.; GOBESSO, A.A.O. Uso da cutina na estimativa da digestibilidade aparente de dietas para equinos. Arquivo Brasileiro de Medicina Veterinária e Zootecnia, v.61, n.6, p.1373-1381, 2009.

STATISTICAL ANALYSIS SYSTEM SAS. SAS user's: guide statistics. Cary: 2000. $211 \mathrm{p}$.

STEIN, R.B.S.; TOLEDO, L.R.A.; ALMEIDA, F.Q.; RODRIGUES, P.H.M.; LIMA, C.G.; CORASSA, A.; SANTOS, T.M. Estimativa da digestibilidade aparente da matéria seca por meio de indicadores internos em equinos. Revista Brasileira de Zootecnia, v.35, n.2, p.504-511, 2006.

TILLEY, J.M.A.; TERRY, R.A. A twostage technique for the "in vitro" digestion of forage crops. Journal British of Grassland Society, v.18, n.2, p.104-111, 1963.

TUFARELLI, V.; CAZZATO, E.; FICCO, A; LAUDADIO, V. Evaluation of Chemical Composition and In vitro Digestibility of Appennine Pasture Plants Using Yak (Bos grunniens) Rumen Fluid or Faecal Extract as Inoculum Source.

Asian-Australian Journal Animal Science, v. 23, n. 12, p.1587-1593, 2010.

VASCONCELLOS, R.S.; CARCIOFFI, A.C.; OLIVEIRA, L.D.; PRADA, F.; PEREIRA, G.T. Utilização de indicadores para estimar a digestibilidade aparente em gatos. Arquivo Brasileiro de Medicina Veterinária e Zootecnia, v.59, n.2, p.466-472, 2007. 
Rev. Bras. Saúde Prod. Anim., Salvador, v.13, n.2, p.410-423 abr./jun., 2012 http://www.rbspa.ufba.br ISSN 15199940

WALLER, J.; MERCHEN, N.;

HANSON, T.; KLOPFENSTEIN, T.

Effect of sampling intervals and digesta markers on abomasal flow determinations. Journal of Animal

Science, v.50, p.1122-1126, 1980.

WATANABE, P.H.; EZEQUIEL, J.M.B.; GALATI, R.L.; BIAGIOLI, B.; SILVA, O.G.C. Indicadores internos indigestíveis para a estimativa das digestibilidades de dietas à base de coprodutos. Revista Brasileira de Saúde e Produção

Animal, v.11, n.3, p.849-857, 2010.
ZEOULA, L.M.; PRADO, I.N.; DIAN, P.H.M.; GERON, L.J.V.; CALDAS NETO, S.F.; MAEDA, E.M.; PERON, P.D.P.; MARQUES, J.A.; FALCÃO, A.J.S. Recuperação fecal de indicadores internos avaliados em ruminantes.

Revista Brasileira de Zootecnia, v.13, n.4, p.1865-1874, 2002.

Data de recebimento: 11/05/2011

Data de aprovação: 21/12/2011 